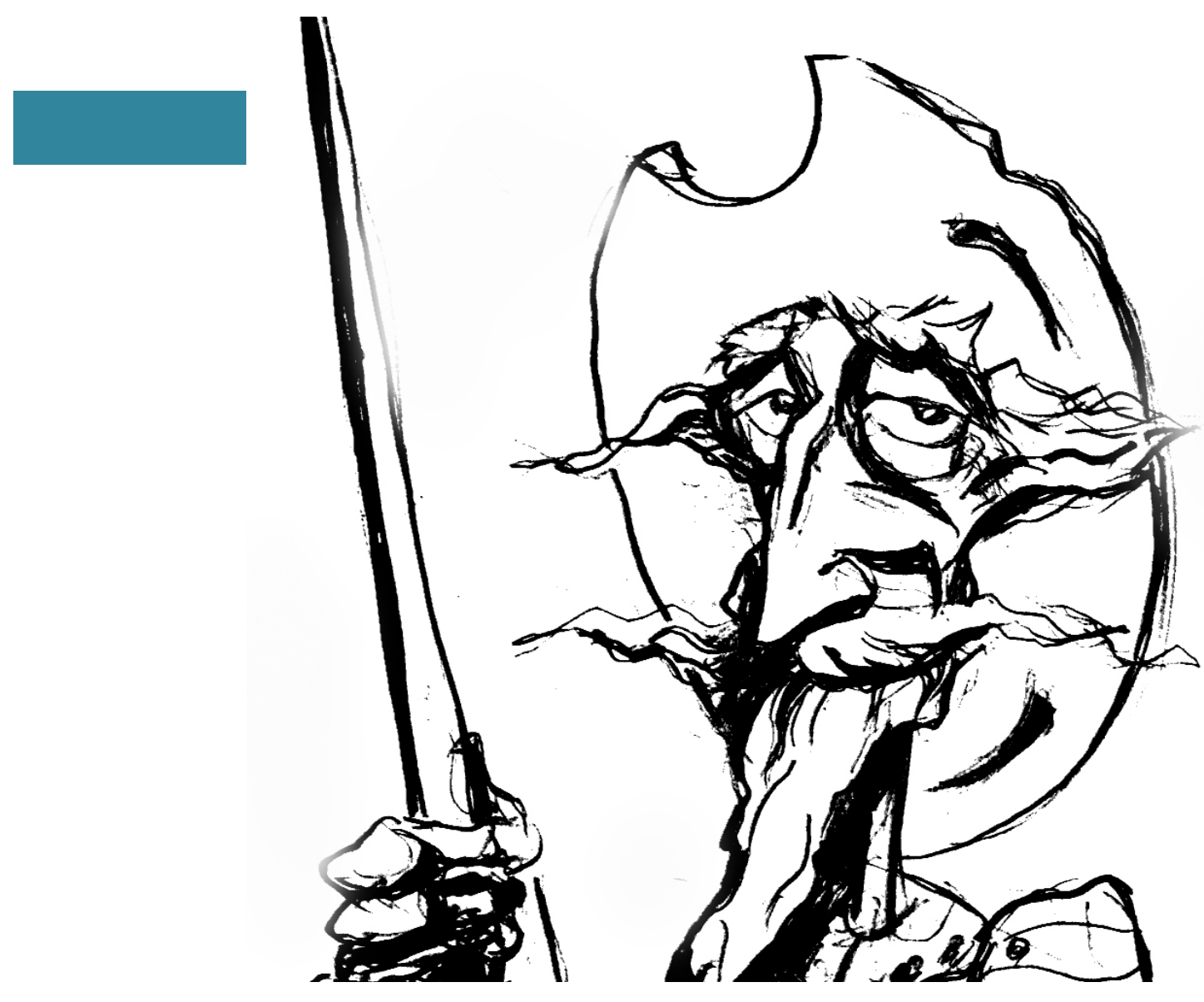

Potencialidad de las discusiones sobre revitalización sindical para pensar la historia reciente del movimiento obrero argentino.

[Ana Elisa Arriaga] 


\title{
Potencialidad de las discusiones sobre revitalización sindical para pensar la historia reciente del movimiento obrero argentino*
}

\author{
Potentiality of Discussions on Trade Union Revitalization to Think the \\ Recent History of the Argentine Labor Movement
}

ANA ELISA ARRIAGA

\begin{abstract}
Resumen
En este trabajo proponemos recuperar el debate sobre revitalización desde su formulación en la literatura anglosajona hasta su recepción en Argentina, con la intención de valorar su pertinencia para pensar las transformaciones de la acción sindical en perspectiva histórica. Partimos de reconocer distintas acepciones del término anglosajón, que a su vez se distanciaron de la utilización que se hizo del mismo en la Argentina. El punto clave de nuestro argumento radica en cómo periodizar y / o caracterizar a nivel local la "crisis de representación sindical" y a partir de ello discutir la periodización utilizada al analizar las

transformaciones del sindicalismo en términos de revitalización, como así también rescatar la potencialidad de algunas estrategias implicadas en ese concepto para pensar trayectorias organizativas y reivindicativas poco visibilizadas en la historia reciente.
\end{abstract}

\section{Palabras clave}

Revitalización - sindicalismo - movimiento obrero historia reciente-Argentina

\begin{abstract}
In this work, we revisit the "revitalization" debate, tracing its origins to the English-language scholarship and then analyzing its reception in Argentina. We intend to appraise its relevance for a historical analysis of transformations in unions' action. First, we recognize the different meanings assigned to the concept in English-language scholarship, which in turn differed from those present in Argentine literature. The key element in our argument lies on how to periodize and / or characterize the "crisis of union representation" at a local level. On that basis, we discuss the periodization used to analyze unions' transformations in terms of revitalization. We also recover the potential in some strategies implied in this concept in order to examine little analyzed organizational paths and protest actions in recent history.
\end{abstract}

\section{Key words}

Revitalization - tradeunionism - labor movement recent history - Argentina

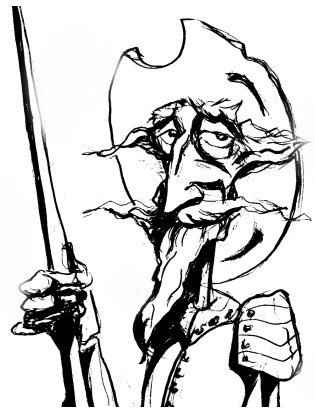

Recibido con pedido de publicación el 15 de octubre de 2017

Aceptado para su publicación el 5 de marzo de 2018

Versión definitiva recibida el 10 de abril de 2018

Ana Elisa Arriaga, Centro de Investigaciones de la Facultad de Filosofía y Humanidades, Universidad Nacional de Córdoba, Argentina; e-mail: ana.elisa.arriaga@gmail.com

\footnotetext{
* Agradezco los comentarios de los evaluadores anónimos de la publicación

Esta obra se publica bajo licencia Creative Commons. Atribución-NoComercial-CompartirIgual Internacional

Arriaga, Ana Elisa "Potencialidad de las discusiones sobre revitalización sindical para pensar la historia reciente del movimiento obrero argentino", Prohistoria, Año XXI, núm. 29, jun. 2018, pp. 115-133.
}

\section{Introducción}

Los debates anglosajones en torno a la revitalización sindical se inscriben en uno más amplio, el de los efectos de la globalización y transformación postfordista del capitalismo sobre la capacidad de acción colectiva de los trabajadores. Dichas trasformaciones perceptibles en los países centrales desde fines de la década de 1970 y comienzos de la siguiente, nos remite a la mutación 
de los modos de producción industrial sostenidos en una aceleración de los ritmos de innovación productiva con alta movilidad geográfica, que suponen todo un despliegue de nuevas tecnologías -automatización- y nuevas formas organizativas -just a time-, basados en una flexibilización de los procesos laborales, los mercados de mano de obra y las pautas de consumo. Aquello que Harvey ${ }^{1}$ denomino "acumulación flexible" implica también un peso significativo de la acumulación financiera y un cambio acelerado en la estructuración del desarrollo desigual tanto entre sectores como entre regiones geográficas, en las que conviven sistemas productivos como el fordismo con sistemas flexibles, artesanales y tradicionales. Visto desde el comportamiento del mercado laboral, la tendencia ha sido el crecimiento del desempleo estructural, y a un desplazamiento hacia los servicios en detrimento de la industria. Esos desplazamientos se acompañaron de cambios en la composición de género y raza a favor de una mayor presencia femenina y migrante, anudada a la proliferación de modalidades flexibles de contratación, cuando no precarias e informales.

Las trasformaciones señaladas implicaron una retirada del Estado en la regulación de las relaciones capital-trabajo, en el marco de un giro hacia recetas neoliberales en la liberación de los mercados, las privatizaciones y la progresiva reducción de la protección social. El escenario no estuvo exento de legislación antisindical en materia de huelgas y movilización. Los diagnósticos pesimistas vieron allí signos de la pérdida de poder de las organizaciones sindicales, expresados en el desplome de su influencia política, en el debilitamiento de su capacidad de negociación colectiva, en la dificultad de movilización y en la caída de las tasas de sindicalización. No faltó quienes atribuyeran parte de la crisis sindical a la esclerosis burocrática de sus estructuras organizativas. Algunas lecturas fueron más allá, al alertar sobre el destino de la clase obrera cada vez más heterogénea o desagregada, asociada a la suerte de un movimiento obrero identificado en sus formas organizativas tradicionales, los sindicatos vistos desde su identidad industrial clásica, donde la pérdida de poder de estos interpelaba directamente las potencialidades de la clase como locus de acción colectiva. ${ }^{2}$

El horizonte del debate sobre revitalización sindical, que aparece especialmente en Inglaterra y EEUU a mediados de los años '90 y comienzos de la década siguiente, interpela a los diagnósticos pesimistas y bucea en una multiplicidad de respuestas sindicales que ponen sobre la mesa nada menos que las estrategias ensayadas para reposicionarse en un contexto de mutación del régimen capitalista. Atendiendo a ello es que nos proponemos explorar ese debate bajo el interés de reconocer problemas, dimensiones de análisis y categorías de uso potencial en el campo de estudios de historia reciente del movimiento obrero. Para ello buscamos en primer lugar recuperar el debate sobre revitalización en su formulación anglosajona, cuya difusión en castellano ha sido escasa y fragmentada. En un segundo momento, recuperamos y problematizamos el modo en que se tematizó dicho debate en los estudios socio-laborales argentinos, preocupados en explicar sobre todo el desempeño del movimiento obrero post 2003. En ese tránsito sostenemos que revitalización no remite a un concepto unívoco, y el núcleo de problemas que atraviesan la

\footnotetext{
${ }^{1}$ HARVEY, David La condición de la posmodernidad, Amorrortu Editores, Buenos Aires, 1999, pp.170-172.

${ }^{2}$ GORZ, André Adiós al proletariado. Más allá del socialismo, Ed. El Viejo Topo, Barcelona, 1981.
} 
cuestión tiene implicancias tanto temporales como temáticas, cuyas especificidades en el escenario argentino se convierten en relevantes núcleos potenciales de investigación histórica. Respaldando esa apreciación presentamos algunas líneas temáticas en las que las categorías y dimensiones emergentes del debate pueden enriquecer las investigaciones en historia del movimiento obrero desde la década de 1970 al presente.

\section{La revitalización sindical desde su formulación anglosajona}

La literatura sobre revitalización tiene como referente una serie de experiencias sindicales surgidas a mediados de los noventa sobre todo en EEUU e Inglaterra, pero también en Australia, Canadá y Nueva Zelanda, Sudáfrica y Brasil cuyo elemento central no ha sido otro que la búsqueda de alternativas para sortear el debilitamiento de los sindicatos como estructuras organizativas que aspiran a representar y proteger a la clase trabajadora. Luego de una etapa en la que parecía que no podía esperarse nada nuevo de los sindicatos, sobre todo de unos sindicatos altamente burocratizados dependientes de sus compromisos estatales para la administración de recursos económicos y servicios, comenzaron a vislumbrarse algunos cambios tendientes a diseñar estrategias para ampliar las bases de representación en la búsqueda de afiliación de nuevos miembros, la utilización de repertorios más disruptivos y radicales frente a los empleadores, y en la ampliación de los horizontes de justicia social incorporando entre sus demandas las necesidades de sectores vulnerables de la fuerza de trabajo, como mujeres o inmigrantes.

Ahora bien, la forma en que la literatura ha tendido a caracterizar y conceptualizar estos procesos no ha sido unívoca, todo lo contrario, bajo el paraguas de la revitalización encontramos estrategias variadas, pensadas en y desde horizontes políticos diversos. En la diversidad no pocos son los autores que consideran que revitalización en los sindicatos es un relanzarse a sí mismos como sujetos políticos, en tanto actores que no solo participan en la negociación colectiva y la regulación laboral, sino también buscan representar intereses políticos y sociales más amplios. ${ }^{3}$

En algunos casos el incremento del activismo político ha puesto de manifiesto toda una serie de estrategias ligadas a la dimensión organizativa y de reconocimiento sindical. Estas estrategias conceptualizadas como "modelo organizacional" o "strategic organising" aparecen con claridad en Australia, EEUU y en el Reino Unido para contrarrestar la brutal caída de la sindicalización, sumado a la legislación flexibilizadora y anti-sindical impuesta desde fines de los años ' $80 .{ }^{4}$ Allí la repuesta sindical se ha caracterizado por la realización de campañas para reclutar nuevos miembros y re-energizar o relanzar a los sindicatos como representantes de los trabajadores frente al empleador. ${ }^{5}$ En este marco EEUU ha sido señalado como el país en el que el sindicalismo ha dado muestras innovadoras con campañas ofensivas frente a

3 HAMANN, Kerstin and KELLY, John "Unions as Political Actors: A Recipe for Revitalization?", in FREGE, Carola and KELLY, John (ed.) Varieties of Unionism: strategies for union revitalization in a globalizing economy, Oxford University Press, Oxford, 2004, pp. 93-116.

4 TOWERS, Brian "Comparisons and prospects: industrial relations and trade unions in North America and Britain", in GALL, Gregor (Ed) Union Organizing. Campaigning for trade union recognition, Routledge, London, 2003, pp.173-190.

${ }^{5}$ BRONFENBRENNER, Kate, Sheldon FRIEDMAN, Richard W. HURD, Ron A. OSWALD et Richard L. SEEBER, Organizing to Win: New Research on Union Strategies. ILR Press, Ithaca, 1998. 
los empleadores organizadas por las centrales sindicales combinando el activismo de base y la experimentación o auto-organización local comunitaria, con campañas de alcance nacional -a favor de candidatos presidenciales pro laborales o por el reconocimiento de derechos a inmigrantes, por ejemplo-, estrategias diseñadas e implementadas por organizadores "profesionales" enviados por las centrales sindicales, sobre todo desde 1995 cuando AFL-CIO ${ }^{6}$ fue conducida por los pro organizadores. ${ }^{7}$

Gran Bretaña también ha experimentado este tipo de estrategias, dando muestras más significativas en la intención por educar en la necesidad de ganar "derechos de organización" en sectores no sindicalizados, en pos de crear un cierto grado de democracia en el marco de la producción capitalista. ${ }^{8}$ La inscripción de estas estrategias en un horizonte de democratización laboral, ha incluido campañas por la recuperación de la legislación protectora del trabajo aprovechando las oportunidades institucionales abiertas por el retorno del Laborismo al gobierno cuyo logro más visible fue la Ley de Relaciones de Empleo de 1999, marco en el que se apostó a internacionalizar demandas y objetivos para incidir a nivel de la Unión Europea e, incluso, en el mercado global, estrategia que aparecería como nodal para el fortalecimiento sindical. ${ }^{9} \mathrm{Al}$ mismo tiempo Gran Bretaña -al igual que Alemania- registra experiencias de fusiones sindicales como la de UNISON, ${ }^{10}$ en la búsqueda de un fortalecimiento por la vía de reducir la competencia intersindical, aumentar la coordinación y capacidad de presión, y en algunos casos, reducir costos organizativos. ${ }^{11}$

Hasta aquí las estrategias englobadas en la revitalización no necesariamente suponen una posición antagónica al sistema capitalista, pues es posible encontrar estrategias de integración- negociación con el Estado como con los empresarios. En este sentido, se incluye por ejemplo al sindicalismo alemán, donde las estrategias predominantes se han caracterizado por la colaboración con los empresarios para implementar cláusulas de flexibilización laboral y descentralización de la negociación colectiva, en términos de preservar recursos institucionales de organización. ${ }^{12}$ En la perspectiva del reposicionamiento institucional desde arriba, y atendiendo casi exclusivamente a ello, también se han formulado apreciaciones escépticas respecto del horizonte

\footnotetext{
${ }^{6}$ American Federation of Labor and Congress of Industrial.

${ }^{7}$ HURD, Richard "Contesting the Dinosaur Image: The Labor Movement's Search for a Future" Cornell University, 2002, ILR school site [http:/ / digitalcommons.ilr.cornell.edu/articles/299/]; FANTASIA, Rick and VOSS, Kim Hard Work: Remaking the American Labor Movement, University of California Press, Berkeley and Los Angeles, 2004; MILKMAN, Ruth L.A. Story. Immigrant Workers and the Future of the U.S. Labor Movement, Russell Sage Foundation, New York, 2006 [www.jstor.org/stable/10.7758/9781610443968.]

8 BACCARO, Lucio, HAMANN, Kerstin, and TURNER, Lowell "The Politics of Labour Movement Revitalization: The Need for a Revitalized Perspective", European Journal of Industrial Relations, 9, 1, 2003, pp. 119-133.

${ }^{9}$ HEERY, Edmund, KELLY, John and WADDINGTON, Jeremy "Union Revitalization in Britain", European Journal of Industrial Relations, 9, 1, 2003, pp. 79-97.

${ }^{10}$ Es el sindicato más grande de Gran Bretaña representa a 1.3 millones de trabajadores de servicios públicos tanto estatales como privados. www.unison.org.uk [consultada en abril de 2015]

${ }^{11}$ TERRY, Michael "Introduction: UNISON and service públic tradeunionism", in TERRY, M. Redefining Public Sector Unionism. UNISON and the future of trade unions, Routledge, London and New York 2001, pp. 5-6.

12 TURNER, Lowell "Institutions and activism: Crisis and opportunity for a German labor movement in decline", Industrial and Labor Relations Review, 62, (3), 2009; pp.294-312.

[http:/ / digitalcommons.ilr.cornell.edu/articles/327/]
} 
sostenible de las estrategias de revitalización. Escepticismo que tiende a señalar distintos límites al "giro organizativo" ensayado por las dirigencias sindicales en términos de las tensiones entre los líderes profesiones y los trabajadores de base o las excesivas dependencias externas en el sostenimiento de la organización. ${ }^{13}$ Pero sobre todo las críticas se han concentrado en el efecto adverso a la democracia sindical, cuando la tendencia a reforzar la centralización de decisiones suele quedar supeditada a los "compromisos" con empleadores y gobiernos aliados, lo que finalmente remite a la distinción entre "reclutamiento" y "reconstrucción del activismo" laboral. ${ }^{14}$

En contrapartida algunas perspectivas de análisis tienden a valorar las estrategias de reorganización impulsadas "desde abajo" o presentadas como alternativas al sindicalismo tradicional. Allí las miradas se han concentrado en la dimensión local - territorial - comunitaria de la posibilidad organizativa del trabajo y la movilización sindical, donde el objetivo no sería otro que ampliar las bases de representación a colectivos dispersos y fragmentados con empleos precarios, y organizarlos sindicalmente como una "comunidad de base" con capacidad de "autoorganización". ${ }^{15}$ El desafío aquí resulta de organizar lo diverso, es decir una fuerza de trabajo heterogénea y subalternaizada sexual y racialmente, destacándose la creciente presencia femenina y migrante en la realización de trabajos precarios o ilegales. Bajo la preocupación de organizar a esos sectores el "sindicalismo comunitario", promueve alianzas con otras organizaciones sociales de base territorial, étnicas o religiosas, en la búsqueda deliberada de promover sentidos de justicia indispensables a la organización de los trabajadores precarios. ${ }^{16}$ Mientras que bajo la etiqueta de "neosindicalismo", se conocen experiencias que focalizan sus estrategias en la construcción de recursos de poder interno, en pos de reducir su dependencia frente a empleadores y gobiernos, donde se apuesta a organizar sobre una base autónoma, la oferta de mano de obra y desde allí presionar en las condiciones de trabajo. ${ }^{17}$ Las estrategias de organización que buscan interpelar a la fuerza de trabajo en su condición de mujeres y/o migrantes -cuestión que atraviesa las diferentes experiencias señaladas- han supuesto desafíos específicos a la propia estructura de poder sindical. ${ }^{18}$ En ese marco el objetivo revitalizador se

\footnotetext{
${ }^{13}$ HEERY, Edmund "Unions and the organising turn: Reflections after 20 years of Organising Works", The Economic and Labour Relations Review, Vol. 26, 4, 2015, p. 545-560.

${ }^{14}$ COHEN, Sheila "Opening Pandora's Box: the paradox of institutionalised" in GALL, Gregor (ed.) The Future of Union Organising: Building for Tomorrow, Palgrave MacMillan, Basingstoke, 2009, pp. 28-44; MOODY, Kim “Union organising in the US: new tactics, old barriers", in GALL, Gregor (ed.) The Future of Union Organising: Building for Tomorrow, Palgrave MacMillan, Basingstoke 2009, pp. 10-27.
}

\section{5}

Desde esta perspectiva se han leído algunas experiencias del "anarcosindicalismo" español. MRTINES, Lucio “¿Todavía organizadores del descontento?. Los retos de las estrategias de renovación en España", en ARXIUS de Ciencias Sociales, núm. 18, Valencia, Junio, 2008, pp. 119134; KÖHLER, Holmy CALLEJA JIMENEZ, José "Conflicto laboral y movimiento sindical en España. ¿Qué queda del movimiento obrero?", en Anuari del Conflicte Social, Barcelona, 2013, pp. 750-768.

${ }^{16}$ HOLGATE, Jane "Community organising in the UK: a 'new' approach for trade unions?" Economic and Industrial Democracy, Vol 36, núm. 3, 2015, pp. 431-455.

${ }_{17}$ MILKMAN, Ruth "Introduction: towards a new labor movement? Organising New York City's precariat", in MILKMAN Ruth and OTT, Ed (eds) New Labor in New York: Precarious Work and the Future of the Labor Movement, Cornell University Press, Ithaca, NY and London, 2014, pp. 1-22. 
constituye en una oportunidad para una mayor equidad, en la que también se problematiza la construcción de una agenda sindical de género y diversidad. ${ }^{19}$

Son precisamente estos aspectos los que incluyeron en el debate a un grupo autores que remiten sus análisis al concepto de "sindicalismo de movimiento social", ${ }^{20}$ considerado por Kim Moody ${ }^{21}$ como un nuevo estadio del sindicalismo que afirma la centralidad de la democracia sindical como una fuente de poder y mirada social amplia, con una posición activa tanto en las calles como en la política, aliándose con otros movimientos pero proporcionándoles una visión y contenido de clase. Este aparece como un sindicalismo democrático, en la búsqueda de movilizar a la clase trabajadora para poder aplicar una mayor presión económica; es militante en la negociación colectiva ya que considera que un retroceso en ella solo lleva a más retrocesos; es político al actuar de forma independiente de los partidos, cualesquiera sean las relaciones entre el sindicato y estos; y finalmente, busca ampliar su base de representación a otros sectores sean estos sindicatos, organizaciones barriales, $\mathrm{u}$ otro tipo de movimientos sociales. ${ }^{22}$

Por su parte Peter Fairbrother quién refiere a experiencias sindicales de Sudáfrica, Brasil y Corea de Sur, utiliza esta categoría pero se distancia de la interpretación que hace Moody considerando, en la línea de Richard Hyman que no habría un nuevo estadio del sindicalismo como forma de contestar a la globalización o a la crisis del fordismo, sino que esa dimensión movimientista se da bajo distintas condiciones como una característica propia del movimiento obrero desde sus orígenes. Desde esta perspectiva el sindicalismo de movimiento social supone una diferenciación del business unionism y una reimplantación de un sindicalismo de clase que implicaría a) estrategias de movilización de base localmente focalizadas, b) experimentación con la acción colectiva más allá de las huelgas y de acciones circunscritas al lugar de trabajo, c) construcción de alianzas y coaliciones amplias y extendidas en la comunidad e incluso internacionalmente, d) y la adopción de políticas emancipatorias en formulación de visiones transformadoras del orden social. ${ }^{23}$

La preocupación por disputar poder al sistema capitalista en su escala internacional, también ha sido terreno fértil en la configuración de alternativas

\footnotetext{
${ }^{18}$ MUNK, Ronald "Globalización, sindicatos y migración laboral: viejos dilemas, nuevas oportunidades", Migración y Desarrollo Vol. 12, núm. 23, Segundo Semestre, 2014, pp. 5-40.

${ }_{19}$ COLGAN, Fiona and LEDWITH, Sue "Gender, diversity and mobilisation in UK Trade Unions" in COLGAN, Fiona and LEDWITH, Sue (ed.) Gender Diversity and Trade Unións. Internationals perspectives, Routledge, London and New York, 2002, pp. 154-185; KEINER, Jan "Gendering Union Renewal: women's contributions to labour movement revitalizatión" in FOLEY, Janis and BAKER, Patricia (ed.) Unions, Equity and the Path to Renewal, UBC Press, Toronto, 2009, pp. 15-38.

${ }^{20}$ Fue enunciado inicialmente por Peter Waterman luego Kim Moody hizo una caracterización general del concepto. WATERMAN, Peter "Social-Movement Unionism. A New Union Model for a World Order?" Review Fernand Braudel Center, Vol. 16, núm.3, Summer, 1993, pp. 245-278.

${ }^{21}$ MOODY, Kim “Towards an International Social-Movement Unionism”, New Left Review I/ 225, September- October, 1997, pp. 52-72.

${ }^{22}$ MOODY, Kim Workers in Lean Worl. Unions in the International Economy, Verso, London-New York, 2001 [1997]

${ }^{23}$ FAIRBROTHER, Peter "Social Movement Unionism or Trade Unions as Social Movements", Employ Respons Rigths Journal 20, 2008, p. 214; HYMAN, Richard "Sindicatos y la desarticulación de la clase obrera", Revista Latinoamericana de Estudios del Trabajo, núm. 4, Año 2, 1996, pp.9-28; HYMAN, Richard Understanding European Trade Unionism. Between market, class and society, Sage, London-New York, 2001.
} 
sindicales. Puestas en evidencia ciertas acciones vinculadas a la generalización de demandas y recursos organizativos supranacionales, se ha prestado atención al impacto de los conflictos obreros en sectores estratégicos de las cadenas globales de valor, dando lugar a un núcleo de reflexiones sobre las estrategias de la fuerza de trabajo frente a la acumulación globalizada. ${ }^{24}$ Siguiendo a Beverly Silver el desafío intelectual allí no es otro que identificar en las respuestas desde abajo, los signos de emergencia de una "nueva clase obrera" en términos de una redefinición de la capacidad de los trabajadores para luchar por mejores condiciones de vida sin dejar de pensar en los alcances de esas luchas en términos de su crítica radical al capitalismo. ${ }^{25}$

Desde lo dicho hasta aquí revitalización sindical lejos de ser un concepto aunque a veces así se lo presente-, aparece como un horizonte de preocupaciones, en el que conviven diferentes perspectivas y procesos. Fueron Carola Frege y John Kelly pioneros en el esfuerzo por sistematizar las distintas estrategias de revitalización comprendidas en la literatura anglosajona. ${ }^{26}$ En una apuesta de síntesis los autores consideraron la necesaria caracterización de la crisis del poder sindical como punto de partida, asumiendo que las tendencias de "declive" o "revitalización" sindical debían atender los factores variables que hacen al poder sindical de un país a otro. ${ }^{27}$ En aras de diagnosticar el "declive" los autores sugieren una serie de indicadores del poder sindical que, como veremos, reaparecen en las interpretaciones sobre los alcances de la revitalización en Argentina. Estos son: niveles de afiliación, cobertura de la negociación colectiva, perdida de definición y agregación de intereses, erosión de las estructuras de representación de intereses (pérdida de peso de comisiones, del funcionamiento de consulta asamblearia) la disminución de la capacidad de movilización en base a la pérdida de la predisposición a la acción reivindicativa y la pérdida de vínculos con partidos políticos.

No obstante lo central es que los autores distinguieron seis tipos de estrategias tendientes a revertir dichos problemas, que pueden servirnos como guía. Ellas son: a) "Organizing", considerada una estrategia hacia afuera que se centra en la adquisición de nuevos miembros tanto creando como fortaleciendo la representación laboral, lo que generaría un aumento en la capacidad de movilización sindical y por lo tanto mayor poder en el mercado de trabajo; b) "Organizational restructuring", centradas en la transformación interna que puede ser a partir de reorganizar la propia estructura, fusionarse con otros sindicatos, los que podría fortalecer la organización sindical mediante la racionalización administrativa y el aumento de recursos al ampliar la escala y aumentar la membrecía, mejorando su poder tanto en el mercado de trabajo como en el sistema político; c) "Coalition building", remite a la construcción de coaliciones con movimientos sociales tales como antiglobalización $\mathrm{O}$ ambientales ampliando redes y recursos de poder claves en términos del componente crítico o antagonista de dichos movimientos, lo que podría favorecer la realización de campañas y la llegada a segmentos de trabajadores

\footnotetext{
${ }^{24}$ MUNK, Ronald, “Globalización, sindicatos..., cit, p. 11.

${ }^{25}$ SILVER, Beverly "Theorising the working class in the twenty first century Global Capitalism", in ATZENI, Maurizio (ed.) Workers and Labour in a Globalised Capitalism: Contemporary Themes and Theoretical Issues, Palgrave Macmillan, 2013, pp. 46-69.

26 FREGE, Carola and KELLY, John "Union Revitalisation Strategies in Comparative Perspective", en European Journal of Industrial Relations, 9, 1, 2003, pp. 7-24; FREGE, Carola and KELLY, John Varieties of Unionism: strategies for union revitalization in a globalizing economy, Oxford University Press, London-New York, 2004.

${ }^{27}$ FREGE, Carola and KELLY, John, “Union Revitalization...”, cit., p. 8.
} 
no representados (inmigrantes, mujeres, entre otros); d) "Partnerships with employers", refiere a la alianza con los empleadores a distintos niveles, nacional por industria o empresa, para proteger o desarrollar las instituciones de negociación que les permitan perseguir nuevos tipos de intereses; e) "Political action", tendiente a proporcionar acceso a recursos de poder institucional que resulte por ejemplo en la legislación laboral más favorable o en un mercado de trabajo regulado corporativamente; f) "Internationals links", los vínculos internacionales podrían mejorar el intercambio de información sobre las empresas multinacionales, mejorando el poder de negociación de los sindicatos y también facilitar las campañas de movilización. La internacionalización de las redes sindicales deviene en un mayor poder político en una economía globalizada. ${ }^{28}$

Esta sistematización tuvo particular impacto en la recepción que en la Argentina se hizo de la temática desde 2007 a la actualidad. Recepción que se ha vinculado a la necesidad de comprender las transformaciones en el mundo sindical tras la salida de la convertibilidad y la implementación de un modelo de crecimiento económico basado en una reactivación del mercado interno, acompañado de políticas estatales activas en materia de estímulos a la demanda a través del salario y de una notable recuperación del empleo. Dicho escenario pronto despertó un renovado interés por los sindicatos aunque, como veremos, desde diversas preocupaciones y refiriéndose a los alcances y límites de la revitalización desde perspectivas disímiles.

\section{Los debates sobre revitalización en las explicaciones socio-laborales de la Argentina contemporánea.}

Resulta ciertamente significativo que desde 2007 arribamos a la difusión local del debate sobre revitalización en la búsqueda de un punto de referencia conceptual para pensar el comportamiento sindical durante la Argentina Kirchnerista, luego de una etapa en la que buena parte de los intelectuales "confinaron al movimiento sindical a los arcones de la historia" ${ }^{29}$ en plena década de 1990 cuando predominó una mirada pesimista sobre las potencialidades organizativas de los sindicatos. Pesimismo visible entre quienes lo analizaron desde una mirada institucionalista donde la clave explicativa fue la necesidad de supervivencia como táctica defensiva desplegada en la negociación con el Estado y el Peronismo. ${ }^{30}$ Pero mucho más profundo entre quienes tendieron a no vislumbrar un buen futuro a los sindicatos en términos del impacto estructural de la desproletarización, en las formas de representación de los sectores subalternos. ${ }^{31}$ Si bien es cierto que desde 2003 los sindicatos tradicionales recobraron protagonismo como promotores del

\footnotetext{
${ }^{28}$ En base a una traducción propia optamos por dejar la nominación de la estrategia en el idioma original dado que con el tiempo varias de ellas se fueron convirtiendo en "etiquetas" con las que suele referirse a este universo de acciones y sus análisis específicos. FREGE, Carola and KELLY, John "Union Revitalitaion...", cit., p. 9.

29 ETCHEMENDY, Sebastián "La doble alianza gobiernos sindicatos en el Kirchnerismo 20032012” en ACUÑA, Carlos ¿Cuánto importan las instituciones?, Siglo XXI, Buenos Aires, 2013, p 95. 30 ETCHEMENDY, Sebastián "Repression, Inclusion and Exclusion: Government-Union Relations and Patterns of Labor Reform in Liberalizing Economies", in Comparative Politics, núm. 3, Vol 36, New York, abril 2004, pp. 273-290; MURILLO, María Victoria “La adaptación del sindicalismo argentino a las reformas de mercado en la primera presidencia de Menem", Desarrollo Económico V. 37, núm. 147, octubre-diciembre, 1997, pp. 419- 446; MURILLO, María Victoria Sindicalismo, coaliciones partidarias y reformas de mercado en América Latina, Siglo XXI, Buenos Aires, 2008.
} 
conflicto social y de la negociación laboral, sobre todo si los comparamos con lo sucedido en la década anterior eclipsada por la visibilidad pública del movimiento piquetero, o de fábricas recuperadas, entre otros. En ese horizonte los debates sobre revitalización sindical vinieron a dotarnos de herramientas para pensar la superación de la crisis de representación sindical, crisis que aquí fue remitida casi exclusivamente al proceso de reestructuración neoliberal iniciado con las reformas del Estado menemistas. ${ }^{32}$

La recepción del concepto de "sindicalismo de movimiento social" ${ }^{33}$ fue paralela y se la utilizó -más o menos explícitamente- para pensar la configuración del Congreso de Trabajadores Argentino (CTA) nacido en 1992, convertido luego en central sindical alternativa hacia 1997. Esta perspectiva dio cuenta de las innovadoras estrategias movimientistas de esta estructura sindical y su apuesta a la expansión de la representación. Se destacó en ese proceso el ensanchamiento del concepto de trabajador, al incluir entre sus afiliados a los desocupados y trabajadores cuentapropistas por ejemplo, pero también la territorialización de sus estrategias de organización desplazándose de las fábricas a los barrios. ${ }^{34}$ No obstante, en la recepción de dicha categoría inicialmente predominó una mirada más preocupada por la matriz "ciudadana" de la movilización. ${ }^{35}$ En un contexto como el de la Argentina Kirchnerista la utilización de la categoría de sindicalismo de movimiento social pareció perder interés en la medida de que la CTA no lograba consolidar su capacidad de articular demandas heterogéneas de la sociedad civil bajo una apuesta movimientista. ${ }^{36}$ Hubo quienes vaticinaron cierto límite de la CTA, en la dilución del componente específico de la condición de explotación capitalista de los trabajadores como eje de articulación de demandas que sustentaran la construcción de alianzas sociales. ${ }^{37}$ Ello se dio también en el marco del giro

\footnotetext{
${ }^{31}$ AUYERO, Javier La protesta. Retratos de la beligerancia popular en la Argentina democrática, Libros del Rojas, Buenos Aires, 2002; DELAMATA, Gabriela “De los 'estallidos' provinciales a la generalización de la protesta en Argentina. Perspectiva y contexto en la generalización de las nuevas protestas", en Nueva Sociedad, núm. 182. 2002, pp. 121-138; SVAMPA, Maristella "De la patria metalúrgica al heavy metal", en SVAMPA, Maristella (ed.) Desde abajo. Las transformaciones de las identidades sociales, Biblos, Buenos Aires, 2000, pp. 121-154.

32 SENÉN GONZÁLEZ, Cecilia y HAIDAR, Julieta "Los debates acerca de la "revitalización sindical y su aplicación en el análisis sectorial en Argentina", en Revista Latinoamericana de Estudios del Trabajo, núm. 22, Caracas, Venezuela, 2009, pp. 5.

33 FERRERO, Juan y GURRERA, Sebastian "El sindicalismo de movimiento social. Algunas reflexiones en torno del concepto", en FERNÁNDEZ, Arturo Estados y sindicatos en perspectiva latinoamericana, Prometeo, Buenos Aires, 2007, pp. 107-129; NEARY, Michael "El trabajo se mueve: una crítica al concepto de 'sindicalismo de movimiento social"" en DINERSTEIN, Ana. y NEARY, Michael El trabajo en debate. Una Investigación sobre la teoría y la realidad del trabajo capitalista, Herramienta, Buenos Aires, 2009, pp. 182-214.

34 ARMELINO, Martín "Resistencia sin integración: protesta propuesta y movimiento en la acción colectiva sindical de los 90. El caso de la CTA", en SCHUSTER, Federico, NAISTATH, Francisco y otros (comp) Tomar la palabra. Estudios sobre protesta social y acción colectiva en la Argentina contemporánea, Prometeo, Buenos Aires, 2005, pp. 275-311; ARMELINO Martín "Kind of blue. Las vicisitudes de la Central de Trabajadores de la Argentina (CTA) durante los años kirchneristas", en PEREZ, Germán y NATALUCCI, Ana (eds.) Vamos las bandas. Organizaciones y militancia kirchnerista, Nueva Trilce, Buenos Aires, 2012, pp. 101-126.

${ }^{35}$ FERRERO, Juan Pablo y GURRERA, Sebastián “El sindicalismo...",cit., p 115.

${ }^{36}$ ARMELINO, Martin, "Kind of...", cit., p. 125.

37 GHIOTTO, Luciana "El eterno retorno al Estado a cerca de la crisis sindical y las potencialidades del 'nuevo sindicalismo' en el capitalismo globalizado" en FERNÁNDEZ, Arturo (ed) Estados y sindicatos en perspectiva latinoamericana, Prometeo, Buenos Aires, 2007, p. 145.
} 
neodesarrollista de la economía argentina, y sus efectos sobre el potencial de recomposición de recursos de poder sindical más tradicionales.

Fueron Sebastián Etchemendy y Ruth Collier pioneros en sostener que la Argentina post 2003 asistía a una revitalización sindical, que no necesariamente remitía a la implementación de estrategias ensayadas por los sindicatos europeos, sino a una transformación del Estado volcado ahora a la intervención económica y a la promoción industrial, marco en el que se restituyeron regulaciones e instituciones laborales clásicas. Allí los protagonistas de la revitalización fueron los representantes del sindicalismo peronista tradicional de la Confederación General del Trabajo (CGT), caracterizada por su estructura jerárquica y vertical basada en monopolios por rama, con pocos vínculos con el sector informal o movimientos sociales nacionales o internacionales. Los autores consideraron este proceso como un resurgimiento bajo la forma de un "neocorporativismo segmentado", 38 neocorporativismo porque reeditaba un patrón de negociaciones tripartitas a nivel de cúpulas sindicales, asociaciones empresarias y gobierno, pactando salarios sectoriales acordes a metas de inflación y un salario mínimo general que se aplicaba al resto de los trabajadores formales o registrados. La apreciación "neo" suponía sin más que el sindicalismo argentino institucionalizado desde la década de 1940 respondía a un modelo corporativo. Mientras que el carácter segmentado, refería al alcance de la representación y la cobertura pues dejaba afuera a un importante segmento de trabajadores precarios $\mathrm{y} / \mathrm{o}$ no registrados, agudizando la diferenciación de la mano de obra. No obstante, para los autores se trataba de un patrón con ciertos rasgos novedosos dado que en la Argentina postneoliberal, el movimiento sindical devino relativamente autónomo del Estado y del sistema de partidos -en comparación con el corporativismo clásico- ya que estos habrían podido ejercer presión para negociar salarios y alentar la movilización a expensas de la aprobación gubernamental.

Por su parte Cecilia Senén González y Julieta Haidar consideraron que en la Argentina de la primera década del nuevo siglo se produjo un "renovado protagonismo de las organizaciones sindicales" y, para explicarlo, apelaron al debate sobre revitalización asumiéndola desde la perspectiva de los estudios comparados como "un conjunto de estrategias variables -según las características institucionales y organizacionales de cada país- que implican en todos los casos un aumento del activismo político sindical". ${ }^{39}$ Desde una perspectiva próxima al enfoque institucionalista y al de la opción estratégica, Senén González y otros han analizado los alcances de la revitalización a partir de tres indicadores clásicos de los estudios sobre poder sindical: aumento de la conflictividad laboral, aumento de la afiliación y de las negociaciones colectivas de trabajo. ${ }^{40}$ La conclusión general es que en la Argentina reciente hay signos de revitalización en la medida de que no solo hay mayor movilización sindical que responde a variables económicas, sino que se ha incrementado la afiliación con la recuperación del empleo formal y también se han producido aumentos salariales y mejoras convencionales tendientes a revertir cláusulas

\footnotetext{
${ }^{38}$ ETCHEMENDY, Sebastian y COLLIER, Ruth “Down but Not Out: Union Resurgence and Segmented Neocorporatism in Argentina: 2003-2007", en Politics and Society, núm. 3, Vol. 35, Septiembre, 2007, pp. 363-401.

${ }^{39}$ SENÉN GONZÁLEZ, Cecilia y HAIDAR, Julieta “La Revitalización...”,cit., p.10.

40 TRAJTEMBERG, David, SENÉN GONZÁLEZ, Cecilia y MEDWID, Bárbara "La negociación colectiva en Argentina, debates teóricos y evidencias empíricas: datos de la encuesta EIL y otras fuentes", en Revista Trabajo, Ocupación y Empleo, núm. 9, MTEySS, Argentina, 2010.
} 
flexibilizadoras de la década anterior. ${ }^{41}$ Sin embargo aquí la revitalización se habría dado en virtud no de una renovación organizativa sino de las estrategias tendientes a reponer y fortalecer la posición institucional de los sindicatos con relación al Estado y el sistema de partidos y es allí donde cobra relevancia la vinculación entre revitalización y "Dialogo Social" -encarnado en el Consejo del Salario Mínimo Vital y Móvil- y en la recuperación de la legislación laboral como lo muestra le Ley de Ordenamiento Laboral de 2004. ${ }^{42}$ Desde esta perspectiva se ha pensado por ejemplo las estrategias del Sindicato de Luz y Fuerza de Capital Federal -exponente clásico de la opción por un sindicalismo empresarial en la década de $1990{ }^{43}$ en clave de revitalización sindical atendiendo a los cambios a nivel de la negociación colectiva. ${ }^{44}$

En contraposición a esta utilización se erige otra perspectiva, cuyos referentes han sido Mauricio Atzeni y Pablo Ghigliani, que aparecerían más próximos a la noción de "sindicalismo de movimiento social" o al menos reponen el carácter innovador de las estrategias sindicales tendientes a fortalecer su acción entre la clase trabajadora. ${ }^{45}$ Centralmente cuestionan la eficacia de los análisis institucionalistas sobre revitalización, desde la aplicación de indicadores como densidad sindical, conflictividad laboral, negociación colectiva y reunificación de la CGT al incorporar datos de las décadas anteriores. Al mismo tiempo advierten que en Argentina si hay algo nuevo estaría expresándose en algunas experiencias de lucha por el reconocimiento mediante un incremento del activismo de base en las comisiones internas, en algunas campañas por la inclusión en convenios colectivos a sectores subcontratados y en el cuestionamiento a dirigencias burocráticas y una notable renovación generacional de activistas, visibles por ejemplo en los conflictos del Subte, Kraft-Terrabusi, entre otros. ${ }^{46}$ Para estos autores el incremento de la negociación colectiva no se origina en el fortalecimiento de las organizaciones ni en nuevas tácticas ofensivas ensayadas por los trabajadores organizados, más

\footnotetext{
${ }^{41}$ SENÉN GONZÁLEZ, Cecilia y DEL BONO, Andrea La revitalización sindical en Argentina: alcances y perspectivas. UNLM, Buenos Aires, 2013.

42 SENÉN GONZÁLEZ, Cecilia y BORRONI, Carla “Diálogo social y revitalización sindical. Una reflexión sobre las relaciones laborales en Argentina post devaluación", en Revista de Ciencias Sociales, DS. FCS. V, 24 núm. 29, Diciembre, 2011, pp.33-53.

43 Este sindicato lideró la Federación Argentina de Trabajadores de Luz y Fuerza siendo protagonista de la opción de concertación/ participación en el proceso de privatizaciones y flexibilización laboral, estrategia interpretada en términos de su novedad respecto de la capitalización de la organización de los trabajadores cambiando sustancialmente su sentido social. GHIGLIANI, Pablo y GRIGUERA, Juan y SCHNEIDER, Alejandro "Sindicalismo empresarial: problemas, conceptualización y economía política del sindicato", Revista Latinoamericana de Estudos do Trabalho, Año 17, núm. 27, 2012, 141-164.

${ }^{44}$ HAIDAR, Julieta "Revitalización sindical en Luz y Fuerza Capital? Aproximaciones desde el análisis de la negociación colectiva" en Senén González, Cecilia y Del Bono, Andrea. La revitalización sindical en Argentina: alcances y perspectivas. UNLM, Buenos Aires, 2013, p. 53-74.

45 ATZENI, Mauricio y GHIGLIANI, Pablo “The resilience of traditional trade unions' practices in the revitalisation of the Argentine labour movement", in PHELAN, Craig (ed.) Trade unions revitalization: trends and prospects in 34 countries, Bern-Oxford, Peter Lang, Düsseldorf, 2007, pp. 105-119; ATZENI, Mauricio y GHIGLIANI, Pablo “The re-emergence of workplace based organisation as the new expression of conflict in Argentina", in GALL, Gregor New Forms and Expressions of conflict at work, Palgrave Macmillan, London, 2013, pp. 66-85.

${ }^{46}$ Para un análisis centrado en casos puede verse ABAL MEDINA, Paula y DIANA MENÉNDEZ, Nicolás Colectivos resistentes, Imago Mundi, Buenos Aires, 2011; VARELA, Paula "¿De dónde salieron estos pibes? Consideraciones sobre el activismo gremial de base en Argentina posdevaluación", Margen, 55, Buenos Aires, 2009; DELFINI, Marcelo y VENTRICI, Patricia "¿Qué ha de nuevo en el sindicalismo argentino? Relaciones laborales y reconfiguración sindical en el kirchnerismo", Trabajo y Sociedad, núm. 27, 2016, pp. 24-41.
} 
bien responde a la coyuntural voluntad política del gobierno; el mismo que le negó sistemáticamente la personería gremial a la CTA, una estructura con fuertes clivajes movimientistas surgida para enfrentar al modelo neoliberal.

Lejos de la categoría de movimiento social, Enzo Benes y Belén Fernández Milmanda reinscriben el debate sobre revitalización sindical en Argentina asumiendo la perspectiva del "poder asociativo" donde muestran las estrategias desplegadas por la Federación Nacional del Transporte de Cargas (FNTC) liderada desde la década de 1990 por Hugo Moyano. ${ }^{47}$ Los autores dan cuenta de una notable expansión horizontal mostrando toda una apuesta organizativa innovadora y ofensiva, que significativamente se remonta a la década de 1970. Allí además revelan la capacidad de la FNTC de ampliar la organización alcanzando a trabajadores en posiciones estratégicas, expansión que se acompañó de la construcción de un poder disruptivo mediante el uso del bloqueo de circulación de mercancías, sumado a toda una lógica de alianzas intersindicales que permitieron a este sindicato de servicios llegar a conducir la CGT y convertirse en protagonista clave del Dialogo Social en tiempos kirchneristas. La fortaleza de este estudio es que claramente permite relativizar las miradas que ponen el acento en el fortalecimiento sindical desde arriba, pero también aquellas que lo supeditan a la inmanencia del activismo de base.

\section{La potencialidades emergentes del debate sobre revitalización para una (o varias) historias del movimiento obrero Argentino.}

En estas páginas hemos intentado mostrar que la revitalización sindical más que un concepto aparece como un horizonte de preocupaciones, en el que conviven diferentes perspectivas teórico políticas y por tanto, distintos referentes empíricos, pero que sin lugar a duda han venido a problematizar dimensiones significativas de las transformaciones organizativas de los trabajadores. Es en ese sentido que dicha diversidad se une en un objetivo que consideramos fértil, el de pensar y dar cuanta de las estrategias para potenciar la acción de las organizaciones del trabajo en un contexto apremiante marcado por la trasformación del capitalismo. Lo cual supone recuperar una preocupación clásica, la que atañe al por qué la representación colectiva de la fuerza de trabajo sigue siendo un horizonte deseable en términos de una sociedad más justa. Parafraseando la pregunta de Behrens, Hamman y Hurd ${ }^{48}$ se vuelve nuevamente necesario saber ¿a quiénes sirve el fortalecimiento de las organizaciones sindicales? y ligado ello, ¿con qué sindicatos efectivamente contamos? La densidad de las escalas temporales que atraviesa a ambas preguntas nos pone ante un terreno fértil para las indagaciones en perspectiva histórica.

Allí más bien nos encontramos con cierta escasez de trabajos históricos que den cuenta de los cambios o permanencias en las estrategias sindicales, atendiendo a la transformación de la capacidad de acción sindical y su relación con otros colectivos sociales, en una perspectiva temporal que se remonte al

47 BENES, Enzo y FERNANDEZ MILMANDA, Belén “El nuevo liderazgo sindical en la Argentina postneoliberal: el caso del gremio de Camioneros", Desarrollo Económico, vol. 52, núm. 205, 2012, pp 31-62.

48 BEHERNS, Martin, HAMANN, Kurt and HURD, Richard "Conceptualizing Labor Union Revitalization", en FREGE, Carola y KELLY, John (Ed.) Varieties of Unionism: strategies for union revitalization in a globalizing economy, Oxford University Press, Oxford, 2004, p. 14. 
menos desde fines de la década de 1970 y comienzos de la década de 1980. Si tenemos en cuenta las preocupaciones que motivaron el debate por la revitalización sindical en Europa y EEUU, es al menos cuestionable su utilización exclusiva para explicar la Argentina desde 2003. Como bien lo sugieren Atzeni y Ghigliani ${ }^{49}$ es necesario caracterizar aquí la "crisis de representación sindical"50 especificando las temporalidades en que se produjeron determinados reposicionamientos sindicales y sus grados de "debilidad" tanto institucionales como en el proceso productivo, en la arena política ${ }^{51}$ y en el mercado de trabajo que no necesariamente fueron paralelos, lo cual además consideramos ameritaría estudios que den cuenta de escalas regionales y sectoriales.

Si los debates sobre revitalización tienen productividad analítica, debemos mirar muy probablemente desde la salida de la dictadura y la reinstitucionalización democrática donde los sindicatos vivieron procesos de movilización por la restitución de derechos previos, al tiempo que sus cuadros dirigentes -diferencialmente afectados por las políticas represivas de la dictadura- pujaban por reposicionarse en las conducciones. En el lento proceso de reinstitucionalización de la vida sindical entre 1984 y 1988, algunos analistas advirtieron la recomposición del modelo sindical tradicional perdiendo capacidad de presión salarial. ${ }^{52}$ Otros estudios sobre las trayectorias específicas de democratización al interior de los sindicatos muestran realidades más heterogéneas ${ }^{53} \mathrm{e}$, incluso, se han destacado algunas experiencias innovadoras como fue el caso de la Asociación de Trabajadores del Estado (ATE) tendiente a la descentralización geográfica de la representación y los recursos que cristalizó en sus estatutos de $1988 .{ }^{54}$ Procesos similares han sido observados en los sindicatos de servicios públicos de electricidad, agua y saneamiento afectados por políticas de descentralización administrativa durante la dictadura. ${ }^{55}$ Un aspecto que aquí adquiere relevancia sería el de tener una perspectiva más amplia respecto del grado de reposición o debilitamiento de los recursos de poder construidos desde los lugares de trabajo, tanto en el funcionamiento de

\footnotetext{
${ }^{49}$ ATZENI, Mauricio y GHIGLIANI, Pablo “The resilience...", Cit., p. 105 -107.

${ }^{50}$ Algunos autores han considerado que dicha crisis en América Latina tuvo como denominador común la crisis de la deuda 1982 y las dificultades que encontraron los sindicatos para reponer sus estrategias ante la implementación de reformas estructurales, lo que no invalida nuestra posición sobre la necesidad de historizar con mayor especificidad la crisis sindical en Argentina, DE LA GARZA TOLEDO, Enrique Los sindicatos frente a los procesos de transición politica, CLACSO, Buenos Aires, 2001, p.15.

${ }^{51}$ Un ingreso a dicho proceso ha sido leído en términos la desindicalización de peronismo y el fortalecimiento de su base clientelar. LEVITSKY, Steven La trasformación del justicialismo. Del partido sindical al clientelista, 1983-1999, Siglo XXI, Buenos Aires, 2005.

${ }^{52}$ MURILlO, María Victoria “¿Las corporaciones o los votos?”, en GARGARELLA, Roberto, MURILLO, María Victoria y PECHENY, Mario (comps) Discutir Alfonsín, Siglo XXI, Buenos Aires, 2010, pp. 139-160.

53 GAUDIO Ricardo y DOMENICONI, Héctor “Las primeras elecciones sindicales en la transición democrática”, en Desarrollo Económico V. 26 núm. 103, octubre-diciembre, 1986.

54 ARMELINO, Martin, "Reformas de mercado y reacciones sindicales en Argentina. Una revisión desde la experiencia de los trabajadores públicos”, Desarrollo Económico, Vol. 55, núm. 216, septiembre-diciembre 2015, pp. 245-278; GORDILLO, Mónica “Normalización y democratización sindical: repensando los '80" Desarrollo Económico, Vol. 53, núm. 209-210, abrildiciembre, 2013, pp.143- 167.

55 ARRIAGA, Ana "Reorganización sindical en los '80: desafíos y oportunidades de dos sindicatos cordobeses de servicios públicos", Polhis, Año 8, núm.16, julio diciembre, 2015, p. 4067.
} 
comisiones internas y cuerpos de delgados como en aquellas cláusulas convencionales que habilitaban el control del proceso de trabajo. Este tipo de recursos pasan a ser claves para la activación de la acción sindical, la defensa del poder adquisitivo del salario y otros derechos, en contextos en los que negociación colectiva se obturó desde arriba y la mayor competencia en el mercado laboral limitó el poder de la huelga durante la década de 1990. En ese sentido, el debate estratégico del activismo sindical y su traducción en prácticas militantes novedosas durante la década de 1980 y comienzos de la década siguiente, es una cuestión que amerita ser indagada en profundidad. Los dirigentes no fueron ajenos a la necesidad de sobreponerse ante los desafíos de una nueva configuración del capitalismo global, marco en el que hubo esfuerzos tempranos orientados a reflexionar sobre las salidas posibles de sus organizaciones en virtud de no perder representatividad en la clase trabajadora. Es elocuente al respecto el contenido de un seminario taller organizado desde la Federación Argentina de Trabajadores de Luz y Fuerza en el año 1987, donde se sostenía que

“...el movimiento obrero no es tan importante en sí mismo, sino en cuanto constituye un mecanismo de cuestionamiento y oposición a modelos económicos injustos. Tal vez sea necesario imaginar nuevos mecanismos que permitan a los asalariados estrechar filas con los modernos marginados (cuentapropistas, subocupados y desocupados), introduciendo móviles de lucha comunes, ya que estos sectores (en franco crecimiento) no pueden reclamar mejores salarios y condiciones dignas de trabajo. [...] Resulta necesario advertir esta realidad, preverla, anticiparla y enfrentarla en forma adecuada" 56

Aun cuando esa orientación haya quedado lejos de la que finalmente se impuso en la federación eléctrica, que allí se haya discutido en esos términos nos pone ante la necesidad de reponer la trayectoria histórica por la que fueron pasando las organizaciones sindicales particularmente tensionadas por la pérdida de representatividad ante el aumento del empleo precario y la desocupación. ¿Hasta qué punto fue posible entonces elaborar diagnósticos y establecer prioridades para ampliar las bases de la organización sindical repensando los alcances de la categoría trabajo? ¿Qué tipo de redes o alianzas potenciaron $\mathrm{u}$ obstruyeron la construcción de una agenda de estrategias sindicales en ese sentido? ¿En qué medida la estrategia de poder sindical ligada a la reposición de los arreglos institucionales obtenidos en la capacidad de presión política del sindicalismo argentino no convivió con otras estrategias? No parece casual que, los sindicatos estatales dónde se produjeron importantes trasformaciones internas en aras de reconfigurar sus recursos de poder como ATE, por ejemplo, se convirtieran en protagonistas de la protesta contra las reformas neoliberales y las privatizaciones durante la década de $1990 .{ }^{57}$ Allí incluso las redes y alianzas internacionales construidas durante los últimos años de dictadura parecerían un tópico relevante en la capacidad de configurar una agenda de estrategias políticas alternativas, ${ }^{58}$ lo que también despierta interés

\footnotetext{
${ }^{56}$ Eléctrum $\mathrm{N}^{\circ} 31$, Sindicato de Luz y Fuerza de Córdoba, 11/12/87, p. 2.

${ }^{57}$ ARMELINO, Martin "Reformas...", cit., p. 256.

${ }^{58}$ GORDILLO, Mónica “Activismo sindical transnacional en el Cono Sur: algunas experiencias" Clepsidra. Revista Interdisciplinaria de Estudios sobre Memoria, V. 4, núm. 7, marzo 2017, pp.68-83
} 
sobre las redes y alianzas sindicales internacionales durante los años posteriores.

Tanto más productivo se torna el debate sobre revitalización para pensar entonces los desafíos del sindicalismo en la década de 1990, cuando a pesar de la concertación de las reformas de mercado por buena parte de las cúpulas, existieron no pocas experiencias de confrontación sindical que ensayaron múltiples estrategias tanto hacia adentro, como hacia afuera. La CTA es una expresión nacional de esas experiencias, pero ¿es esa organización el principio y el fin de una apuesta? como tendió a ser asumida. ${ }^{59}$ Algunos estudios muestran tangencialmente que hubo experiencias diversas. Aquí otra vez aparece ATE como ejemplo de la construcción de todo un abanico de estrategias desde la fusión, a campañas por el reconocimiento que dieron lugar al incremento de la afiliación. También se le atribuye una "refundación de las practicas sindicales" que estuvieron especialmente enmarcadas en los distintos escenarios provinciales, como espacios políticos administrativos singulares en los que se desarrollaron distintos procesos de innovación en los repertorios y en las alianzas. ${ }^{60}$ Claro que ATE no agota la experiencia de CTA y fuera de ella también es posible vislumbrar procesos significativos. El caso del Sindicato de Luz y Fuerza de Córdoba, da cuenta de estrategias diversas en ese sentido, pues se destacó por enfrentar con éxito el proceso de privatización de la empresa provincial de energía, iluminando otras posibilidades en el vínculo entre la forma sindical y la estrategia política. ${ }^{61}$ Primero jugó un rol de oposición interna a la Federación convertida en holding empresario hacia 1992, sin dejar de pertenecer a la misma y sin romper con la CGT como si lo hizo su par marplatense. Puertas adentro ensayó distintas estrategias desde la creación sindical de una cooperativa de trabajadores que competían con empresas privadas en áreas tercerizadas de la empresa pública, hasta consolidar en el año 2000 un amplio movimiento social en defensa de la empresa estatal como garante de la reproducción social de todos los trabajadores. Los modos en que esas respuestas suturaron en una representación más o menos exitosa en los contextos regionales, con vaivenes entre estrategias movimientistas, clasistas y corporativas, es una evaluación que se torna relevante con respecto a sus consecuencias para el futuro de la forma sindical.

Así las cosas los albores del siglo XXI dan cuenta de unos sindicatos que sobrevivieron al neoliberalismo $\mathrm{y}$, en algunos casos, se fortalecieron -incluso aquellos que optaron por la participación empresaria devinieron en administradores de servicios públicos re-estatizados, como la FENTOS ${ }^{62}$ en Aguas Argentinas- de allí que en este tránsito posiblemente estemos menospreciando una diversidad de estrategias de recomposición/revitalización sindical con trayectorias heterogéneas no fácilmente subsumibles a tipologías cerradas de las perspectivas institucionalistas de las respuestas sindicales, en

\footnotetext{
${ }_{59}$ SVAMPA, Maristella La sociedad excluyente, Taurus, 2005, Buenos Aires, pp. 223; VARELA, Paula "Estado y sindicatos en la argentina post devaluación. El retorno del debate estratégico", Critica Marxista, núm. 38, IFCH, Sao Pablo, 2014, pp.109- 202.

${ }^{60}$ COLLADO, Patricia "De la crisis a la refundación sindical. El caso de la Asociación de Trabajadores del Estado-ATE, en la provincia de Mendoza, Argentina", Revista Latinoamericana de Estudios del Trabajo, $2^{\circ}$ Época, núm. 23-24, 2010 p. 171-194.

${ }^{61}$ DROLAS, Ana "Modelo sindical y acción política. Las experiencias diferenciales de dos sindicatos del sector eléctrico", Revista Trabajo y Sociedad, núm. 12, Vol. XI, otoño 2009, Santiago del Estero.

${ }^{62}$ Federación Nacional de Trabajadores de Obras Sanitarias.
} 
términos de concertación/ negociación/ oposición al modelo neoliberal, ${ }^{63}$ para reponer esas singularidades creemos que los debates sobre revitalizaciones condensados en las dimensiones señaladas por Frege y Kelly-, habilitan otros recorridos analíticos que no han sido explorados a la hora de dar cuenta de las respuestas sindicales frente a los cambios en el régimen de acumulación de las últimas décadas.

En este itinerario creemos que tiene particular potencialidad estudiar las estrategias construidas localmente, considerando la dimensión regional/ territorial de la acción sindical. Dicha escala cobra interés sobre todo si atendemos a las transformaciones de la movilización social argentina post dictadura y la dinámica propia de la protesta laboral y sindical de la década de 1990, en la que parecieran confluir procesos de descentralización de la negociación colectiva con una regionalización del conflicto social que ha sido capturado por la literatura en términos de acción sindical cupular de concertación/ pérdida de representación sindical en el conflicto laboral/ protagonismo de nuevos movimientos sociales. ${ }^{64}$ No obstante, desde 2010 una parte importante del que fuera el "movimiento piquetero" disputa el reconocimiento gremial de su organización, en la Confederación de Trabajadores de la Economía Popular, inscribiendo su matriz organizativa bajo la forma sindical. ${ }^{65}$ Ello nos remite a la necesidad de repensar e indagar con detenimiento las trayectorias históricas de las experiencias de imbricación sindical en las lógicas de movilización colectiva y renovación de estrategias laborales durante la década de 1990, especialmente en los espacios regionales donde los sindicatos estatales fueron protagonistas claves. ${ }^{66}$

Los debates sobre revitalización en su formulación comunitaria o en clave de sindicalismo de movimiento social, pueden orientar análisis de la singular configuración histórica en los alcances de las alianzas intra y extra sindicales, las modalidades de esa imbricación no solo en términos de la experimentación en la utilización de repertorios contenciosos más o menos novedosos, también en el grado de experimentación en las estrategias de ampliación del universo de organizados desde los trabajadores precarios a los flexibilizados de la modernización productiva, y los modos en que esto alcanzó a plasmarse en las estructuras organizativas de los sindicatos. También cabe reponer a nivel local y regional el persistente lugar de los liderazgos sindicales en la preservación -o no- de recursos institucionales mediante su participación legislativa en los gobiernos provinciales, y sus posiciones frente a reformas sociales, laborales $\mathrm{y} / \mathrm{o}$ previsionales.

Finalmente, no podemos soslayar las interpelaciones que el movimiento feminista o por los derechos de las mujeres y la equidad de género viene haciendo a los sindicatos y su impacto en la agenda gremial, algo escasamente abordado en el ámbito de los estudios históricos sobre sindicatos. Los recientes Paros de Mujeres -el 19 de octubre de 2016 de alcance Nacional y los

\footnotetext{
${ }^{63}$ MURILLO, Victoria Sindicalismo..., cit., p. 78 y ss.

${ }^{64}$ SVAMPA, Maristella La sociedad excluyente, Taurus, Buenos Aires, 2005.

${ }^{65}$ ABAL MEDINA, Paula “Los movimientos obreros organizados de Argentina (2003-2016)", en ABAL MEDINA y Otros ¿Existe la clase obrera?, Capital Intelectual, Buenos Aires, 2017, pp. 2162.

${ }^{66}$ AIZICZON, Fernando "Tras las huellas del Cutralcazo. Una lectura desde el sindicato docente ATEN", Estudios, núm. 26, Córdoba, 2011, pp. 95-110; PETRUCELLI, Ariel Docentes y piqueteros. De la huelga de ATEN a la pueblada de Cutral Có, El Cielo por Asalto, Buenos Aires, 2005.
} 
Internacionales del 8 de Marzo de 2017 y 2018- ${ }^{67}$ convocados en nuestro país en el marco de la lucha contra la violencia de género; se constituyeron en un hito en la capacidad de agencia de las trabajadoras. Ello ha dejado en cierta perplejidad pública a las conducciones sindicales, mientras se intensifican los debates sobre los límites de las organizaciones sindicales frente a la equidad de género en las diversas dimensiones de la vida organizativa del trabajo y, se multiplican los encuentros de mujeres sindicalistas en pos de la construcción de una agenda de estrategias transformadoras. ${ }^{68}$ Los debates sobre revitalización sindical aquí pueden iluminarnos en varias direcciones, no solo en la formulación de preguntas sobre la trayectoria histórica de las estrategias sindicales construidas en torno abarcar las políticas de equidad, también en la receptividad del movimiento de mujeres por parte de las dirigencias sindicales.

Argentina no ha sido ajena a la tendencia de feminización de la fuerza de trabajo, mucho más marcada aquí durante la década de $1990 .{ }^{69}$ Los llamados de atención respecto de las divergencias entre representación sindical y participación femenina en el mercado laboral y en la acción colectiva no son nuevos en los estudios históricos, sin embargo carecemos de análisis que hayan reconstruido cómo fueron asumidas estas cuestiones por los sindicatos, en el pasado reciente. Significativamente a fines de 1973 se creó el Departamento de la Mujer de la en la CGT y pos dictadura existieron experiencias organizativas como la Mesa de Mujeres Sindicalistas y el Movimiento Nacional de la Mujer Sindical ambas visibles en $1984,{ }^{70}$ sin embargo sabemos muy poco acerca de la emergencia y disolución de estas experiencias y sus alcances sobre la definición de estrategias sindicales por la equidad. Es allí donde creemos que las diversas estrategias que atraviesan los debates sobre revitalización sindical también pueden orientar indagaciones sobre el modo que se fueron diseñando políticas o generalizando demandas por la equidad de género dentro de las organizaciones sindicales. No solo a partir de perspectivas preocupadas por los clivajes movimientistas, comunitarios o territoriales, desde donde por ejemplo sería deseable reponer en perspectiva histórica los encuentros y desencuentros del movimiento feminista y el movimiento obrero en las últimas décadas. ${ }^{71}$ También desde perspectivas más institucionalistas de la revitalización sería

\footnotetext{
${ }^{67}$ Documento "Nosotras paramos", Colectivo NI UNA MENOS

https:/ / www.facebook.com/notes/ni-una-menos/nosotras-paramos/544964935694693, [consultado el 20 de octubre de 2016].

${ }_{68}$ Una de esas experiencias ha sido el $1^{\circ}$ Encuentro Nacional de Mujeres Sindicalistas en noviembre de 2016, puede consultarse "Hacer visible lo invisible" http:/ / agnprensa.com/hacer-visible-lo-invisible/ [Consultado el 15 de noviembre de 2016].

69 TRAJTEMBERG, David "Negociación colectiva durante 2003-2007, un análisis desde la perspectiva de género." en $9^{\circ}$ Congreso Nacional de Estudios del Trabajo, Buenos Aires, 5, 6 y 7 de agosto, 2009, http:// www.aset.org.ar/congresos/9/contenido.htm

70 AZPIAZU, Eliana "Participación de las mujeres e institucionalidad de la problemática de género en el sindicalismo argentino", en $12^{\circ}$ Congreso Nacional de Estudios del Trabajo, Buenos Aires, 5, 6 y 7 de agosto, 2012, http://www.aset.org.ar/2015/grupos.htm?groupId=6; CHEJTER, Silvia y LAUDANO, Claudia Género en los movimientos sociales en Argentina, CECYM, Buenos Aires, 2001.

${ }^{71} \mathrm{Al}$ respecto Jan Keiner en el marco de los debates sobre revitalización sindical focaliza en las contribuciones de la organización de las mujeres y la extensa discusión dentro de los análisis feministas de los sindicatos, como un elemento dinamizador clave para la revitalización del movimiento obrero. KEINER, Jan “Gendering Union Renewal: women's contributions to labour movement revitalizatión", Gender and Work Database, April 18, 2006

[http:/ /libgwd.cns.yorku.ca/gwd/wp-

content/uploads/Kainer_Gendering_Union_Renewal.pdf]
} 
deseable atender a estrategias de organización de trabajadoras en sectores económicos del comercio y servicios, fuertemente impactados por políticas de flexibilización del empleo. Indagar desde perspectivas preocupadas por restructuraciones de las organizaciones sindicales, los alcances de estrategias de creación de "secretarias de género, equidad y diversidad" en los sindicatos o el impacto de cláusulas de equidad en las negociaciones colectivas, sin olvidar las redes y agencias internacionales específicas que promovieron determinadas estrategias, por mencionar solo algunos de los tantos temas poco explorados.

En definitiva, y desde una perspectiva crítica, creemos que los problemas, dimensiones y categorías que del debate sobre revitalización emergen, tienen mucho potencial a hora de delimitar preguntas, variables y objetivos para reponer en profundidad histórica aquellas transformaciones, tensiones y ambigüedades perceptibles en las estrategias organizativas y reivindicativas de los y las trabajadoras, en un contexto de reconfiguración de los mecanismos de explotación de clase.

\section{A modo de cierre}

En este trabajo hemos recuperado los tópicos centrales de la discusión sobre revitalización sindical desde su formulación anglosajona buscando problematizar sobre todo la recepción argentina de dicho debate. Mostramos como algunos de los sentidos sobre revitalización sindical fueron aplicados aquí casi exclusivamente a la etapa post 2003, sin considerar su utilidad para el análisis de otros contextos históricos y otras experiencias en las que se planteaban oportunidades políticas para recomponer los sindicatos y repensar su rol, como la reapertura democrática o la resistencia al neoliberalismo. En ese sentido es que inicialmente consideramos necesario precisar aquí los alcances de la "crisis de representatividad sindical", reconociendo distintas dimensiones y temporalidades de la misma.

Nuestro diagnóstico se nutre de algunas experiencias o casos que aparecerían como disonantes al respecto de aquellas interpretaciones instaladas sobre las impotencias o debilidades del mundo sindical para dar respuesta a los nuevos tiempos de un capitalismo en mutación. Interpretaciones que a veces han tendido a subestimar las potencialidades critico disruptivas de la acción sindical, en base a una suerte de generalización de los comportamientos cupulares a todo el comportamiento de la rama o, también, a una invisibilización de las posibles variaciones regionales. Esa generalización suele operar a condición de hacer extensivos análisis que despliegan mecánicamente tipologías del comportamiento sindical que no permiten dimensionar la complejidad de la dinámica de la acción sindical territorial, comunitaria o movimientista que puede expresarse en distintos niveles de tensión y convivencia de estrategias diferentes.

Finalmente recuperar el debate sobre revitalización para redimensionar en perspectiva histórica el devenir de las organizaciones sindicales, implica expresamente el no renunciar al potencial crítico de las mismas en una Argentina para nada exenta de explotación en niveles de "esclavitud" y "trata" desigualmente distribuidas en términos de género, nacionalidad y pertenencia étnica. Es en ese telón de fondo en el que no podemos dejar de considerar que un factor relevante para dar respuesta a ello se vincula directamente con las posibilidades/imposibilidades de organización y representación de los trabajadores/as implicados. Directa o indirectamente las formas institucionales 
hegemónicas que fue asumiendo la organización sindical, afectaron la posibilidad de representación de los y las trabajadoras, pero como hemos intentado mostrar estas no son inmutables. Reponer el carácter cambiante de esas formas en las últimas décadas, atravesadas por cambios estructurales de envergadura, resulta de vital interés al presente. 